\title{
O Mosaico Literário em O AMANUENSE BELMIRO
}

\author{
Celia Tamura*
}

\section{RESUMO}

O presente artigo visa apresentar as fontes literárias de Cyro dos Anjos (1906-1994) utilizadas para compor o romance $O$ amanuense Belmiro (1937), revelando-as como uma das modalidades do quixotesco. Homem de muitas leituras, o protagonista Belmiro evoca, a cada momento, uma obra ou passagem literária, assim como canções da infância e mitos fabulosos.

PALAVRAS-CHAVE: Cyro dos Anjos, $O$ amanuense Belmiro, romance brasileiro, mito, quixotesco.

\section{ABSTRACT}

This paper analyses the literary sources used by Cyro dos Anjos (1906-1994) for composing the novel $O$ amanuense Belmiro (1937), revealing them as one of the Quixotesque's literary modalities. As a man of a vast reading, the protagonist Belmiro evokes, at each moment, a literary work or its fragment, as well as childhood's song and fabulous myth.

KEYWORDS: Cyro dos Anjos, O amanuense Belmiro, brazilian novel, myth, Quixotesque.

"È un uomo fatto di libri, di favole e di fantasmi. La materia di cui si nutre viene da un altro mondo. Ed è questa alterità che permette all'autore di rivelare la realtà di un mondo atuale e presente, di un mondo vero".

(BERARDINELLI, 2002, p.344)

O engenhoso fidalgo Dom Quixote de La Mancha (1605), a grande obra de Miguel de Cervantes (1547-1616) fundadora do romance moderno, é a principal referência em $O$ amanuense Belmiro (1937), pois, além das citações comparativas entre o amanuense e o Cavaleiro da Triste Figura, a noção de quixotesco permeia toda a obra de Cyro dos Anjos, exercendo, assim, a função de mito secularizado. Uma das modalidades do quixotesco apresentada nesse romance é o papel da leitura como formadora do caráter da personagem Belmiro, como ocorre com Dom Quixote, que lê seus romances de cavalaria, por eles se apaixona e sai, então, em busca de aventuras para reformar o mundo. Inspirado pelas histórias de cavaleiros andantes, faz de si mesmo um deles. Belmiro, por sua vez, sente-se moldado por suas leituras e vê o mundo pela ótica da literatura, tornando-se um rapsodista, ao escrever em seu Diário.

Tanto na personalidade de Dom Quixote quanto na de Belmiro, a realidade onírica revela-se mais verdadeira que a cotidiana. O crítico italiano Alfonso Berardinelli, em seu artigo "L'incontro con la realtà", observa que, na obra de Cervantes, a "descoberta da realidade", a sua representação "realística", nada mais é que um aspecto de sua ideia de realidade e um interrogativo de seu significado. Berardinelli discorre acerca da diferença entre a realidade e a verdade, descrevendo o Cavaleiro da Triste Figura como um homem feito de livros, de fábula e de fantasmas. Somente essa alteridade manifestada é que permite revelar a realidade de um mundo atual e presente, de um mundo verdadeiro

\footnotetext{
* Doutoranda do Curso de Teoria e História Literária do Instituto de Estudos da Linguagem - UNICAMP. E-mail: celiatamura111@yahoo.com.br. O presente trabalho foi realizado com o apoio do Conselho Nacional de Desenvolvimento Científico e Tecnológico - CNPq - Brasil.
} 
(BERARDINELLI, 2002, p.344). Pois a realidade é sempre o resultado de um pacto convencional, no qual os fatos, para serem reconhecidos como fatos, devem ser também valores. Se os valores forem separados dos fatos, tornam-se irreais. E os puros fatos, espoliados de valores, são instáveis: impõem-se sem merecê-los. Por isso, "o mundo sem Dom Quixote não seria mais real, porém menos" (BERARDINELLI, 2002, p.348).

Da mesma forma, o também italiano Claudio Magris comenta que é impossível imaginar o romance sem o mundo moderno, pois o romance é o gênero literário por excelência da transformação universal que configura o indivíduo na "prosa do mundo". O sujeito sente-se inicialmente estrangeiro na vida, fragmentado entre sua nostálgica interioridade e uma indiferente e desconexa realidade exterior. Magris reitera o que já havia afirmado Georg Lukács, segundo o qual Dom Quixote de La Mancha constitui o primeiro grande romance da literatura mundial, que expõe a consciência de um mundo alienador. O mundo da épica homérica era uma totalidade que antecipava a divisão em mundo interior e mundo exterior. Esta totalidade existe agora apenas como o objeto de uma busca, como um ideal, o de reintegrar subjetividade e objetividade (LUKÁCS, 2000, p.106-107).

As distâncias entre os desejos do indivíduo, de um lado, e a realidade, de outro, não é uma exclusividade do Quixote, lembra lan Watt, segundo o qual a confusão dos desejos românticos com a verdade histórica é uma tendência universal. Em essência, Dom Quixote reage inconscientemente às mesmas pressões imaginativas que se manifestam nos romances de cavalaria: personifica a tentativa de corrigir o verdadeiro curso da história desde os dias heróicos da idade de ouro (WATT, 1997, p.76).

Para Ortega y Gasset, o romance de aventuras, como o conto e a épica, é a maneira ingênua de viver as coisas imaginárias e significativas. O romance realista é uma segunda maneira, oblíqua, pois necessita da primeira: requer a miragem para ser vista como tal (ORTEGA Y GASSET, 1967, p.148). Ortega considera o mito como sendo o ponto de partida para toda poesia, inclusive a realista. No entanto, nesta acompanhamos o mito em sua queda. O tema da poesia realista é o desmoronamento de uma poesia. Não são as realidades o que nos comovem, mas sua representação, ou seja, a representação da realidade (ORTEGA Y GASSET, 1967, p.152).

Tais concepções do quixotesco podem ser aplicadas às personagens criadas por Cyro dos Anjos, autor que utiliza o mito de Dom Quixote como seu principal arquétipo em toda a sua obra ficcional e ensaística. No mosaico literário que constitui o romance $O$ amanuense Belmiro, a figura do Quixote é associada a Belmiro em diversas passagens: "Amigo Quixote, todos os cavaleiros andantes já se recolheram e não há mais dulcinéias" (ANJOS, 2002, p.59); "Arrependo-me. Glicério é, afinal, um excelente moço e nenhuma culpa tem de não me ter sido útil na aventura em que muito me aproximei do herói manchego" (ANJOS, 2002, p.90). A própria caracterização do amanuense é quixotesca, já que é magro, alto e nele predomina o lado espiritual mais que o físico.

São inúmeras as referências a obras de outros autores como Baudelaire, Heine, Platão, Amiel, fazendo de $O$ amanuense Belmiro um grande mosaico literário e quixotesco: "Estive refletindo, esta tarde, em que, no romance, como na vida, os personagens é que se nos impõem. A razão está com Monsieur Gide: eles nascem e crescem por si, procuram o autor, insinuam-se-Ihe no espírito" (ANJOS, 2002, p.95); "Eis aí, respondeu. Vocês querem ser literatos sem ter lido Camilo. 'Perrexil' é o estimulante do pensador. Perrexil é a Musa" (ANJOS, 2002, p.106). Aristóteles de Estagira, nome adotado por Silviano, para enganar moças de subúrbio, alude ao termo "gira", que significa louco, usado para denominar o 
médico Otelo, que "não acredita na medicina (salvo na neurologia, em que - talvez por ser meio gira - se tornou grande especialista) e faz humorismo quando o procuram para outras moléstias" (ANJOS, 2002, p.187). Além disso, Belmiro retrata seus momentos de leitura, como quando lê Hermann e Dorotéia, no parque, enquanto seu acompanhante Carolino dá voltas de bicicleta. Os livros, para o amanuense, não são simples objetos materiais, mas sim seres repletos de vida e de encantamento, ao menos durante a noite, momento em que predomina o seu lado fantasista, pois as horas noturnas correspondem aos "domínios proustianos da insônia, onde os pensamentos não têm contornos nítidos e a consciência se confunde" (ANJOS, 2002, p.115):

Os livros, em desalinho, que à noite me parecem, não coisas inertes, mas seres encantados, mundos vivos, a se desdobrarem e ampliarem para que personagens e paisagens se movam, cá estão reduzidos à imobilidade. Nem pressentimentos, nem angústias. A aurora, como nos livros clássicos, entrou em carro triunfal e expulsou as sombras (ANJOS, 2002, p.115-116).

O amor pelos livros, nascido já na infância, é aprofundado durante a juventude, quando em companhia dos chamados "literatos", em Belo Horizonte. Ao abandonar o projeto de se tornar agrônomo, Belmiro é repreendido pelo pai, mas fora este quem semeara o gosto pelas letras, quando escrevia artigos para a Gazeta Caraibense, em propaganda da vida rural:

Mas, ao cabo de contas, foi no velho que começou o desvio da linhagem rural. Não citavas o teu Vergílio, pai Belarmino? Na verdade estavas mais próximo dos clássicos (lembro-me de tua predileção um tanto tendenciosa para o Horácio...) do que da tua gleba. Words... Words... Como diria Prudêncio, esclarecendo que a exclamação foi do Hamlet (ANJOS, 2002, p.28).

No romance $O$ amanuense Belmiro, uma das referências literárias mais importantes é a obra de Proust, Em busca do tempo perdido. A primeira surge no quarto parágrafo, no qual se descreve o processo de adormecimento do protagonista, mas que termina comicamente, com o sono interrompido pelo latido de um cão. Nessa passagem, o imaginário literário é desfiado pela realidade exterior, de forma irônica, e Belmiro acaba por assumir o papel quixotesco, tendo a sua subjetividade obrigada a se ajustar à objetividade, à realidade concreta:

Já estava palmilhando a terra vaga do sono, para frente, para trás, segundo a luta surda que se trava em nós, entre uma parte do eu, que aspira ao abandono, e outra inconsciente que inspira o adormecer, imagem da morte; ganhava-me o corpo uma doce lassidão, e o espírito se ia contagiando do torpor que afrouxava os nervos; apenas impressões vagas, prestes a se apagarem, me vinham das coisas, e a uma reminiscência tênue, quase a esvaecer, reduzia-se esta lembrança permanente com que, no estado de vigília, a memória sustenta, a cada instante, nossa precária unidade psíquica, ligando o momento que passou ao momento presente. De corpo e espírito, achava-me, pois, preparado para o repouso e já me aconchegava, repetindo, instintivamente, as posições do embrião no ventre materno, quando, arrancando-me daquele suave quebranto, o cão dos fundos se pôs a ladrar, com um método que 
indicava disposição sólida de latir pela madrugada toda. Previ a catástrofe, em sua extensão, e repreendi-me por já não ter ministrado uma "bola" ao canino demônio (ANJOS, 2002, p.29).

Belmiro cita Montaigne, aludindo ao episódio do cão, mas resumindo uma das ideias centrais do livro: "A alma descarrega suas paixões sobre objetos falsos, quando lhe faltam os verdadeiros" (ANJOS, 2002, p.31). Assim como a fúria dos Borbas arrefece ao jogar a esmo um sapato, como se se atirasse contra o cão barulhento, o desejo humano também precisa de sapatos velhos para que sirvam de objetos imaginários das suas paixões, quando não há os verdadeiros. "Parece que, abalada e comovida, se perde em si mesma se não Ihe damos presa; cumpre fornecer-Ihe sempre objeto em que possa aplicar-se e atuar" (ANJOS, 2002, p.31). É o mesmo processo psíquico que ocorre quando Belmiro encontra Carmélia, e pode, então, revesti-la com seu mito constituído pela donzela Arabela e por Camila:

Foi uma visão extraordinária. Pareceu-me que descera até a mim a branca Arabela, a donzela do castelo que tem uma torre escura onde as andorinhas vão pousar. Pobre mito infantil! Nas noites da fazenda, contava-se a história da casta Arabela, que morreu de amor e que na torre do castelo entoava tristes melodias (ANJOS, 2002, p.38).

Destaca-se, no romance, a importância da leitura para a formação do caráter individual das personagens, cada qual concentrando seus interesses numa determinada categoria de obras, cada qual criando assim a sua concepção de mundo, por meio das leituras de sua preferência. O grupo de amigos constitui-se de três "literatos": Belmiro, Silviano e Redelvim, cada um dos quais escritor de um diário. Além destes, Jerônimo, que abraçara a carreira religiosa, lê obras como La cuisine des anges, de Luc Benoist. Redelvim lê livros políticos, socialistas, sobretudo Marx, e é engajado socialmente, porém adepto de um socialismo romântico. Belmiro também escreve para que um dia seu livro seja publicado, porém não tem certeza dessa publicação. Seu Diário, durante o ano de 1935, cai nas mãos do delegado de Polícia, que o lê e toma conhecimento dos sonhos românticos do amanuense, provocando grande vergonha a este. Acerca da escrita de diários, o amanuense cita uma passagem de Gregorio Marañon: "En el hombre adulto la práctica del Diario equivale a una supresión progresiva de la personalidad activa, social, de su autor. En realidad un Diario equivale a un lento suicídio" (ANJOS, 2002, p.194), ilustrando a frustração sentida por não ter encontrado rumos práticos ao longo da vida.

Belmiro tem acesso aos diários dos amigos, Silviano e Redelvim, secretamente. De Silviano, conhece, por meio dos escritos, estudos filosóficos, sobretudo a concepção do fáustico, "a vida estrangulada pelo conhecimento", posteriormente explicada pelo próprio Silviano:

- Bem, o fáustico de Amiel se enquadra no definido por Spengler. Mas, quando disse que o "mito Donzela Arabela" é um símbolo fáustico, não quis significar que você, Porfírio, ande em tais altitudes. Apenas me pareceu que essa aspiração do imaterial e do intemporal feminino, também minha, é, de algum modo, uma inquietação fáustica... (ANJOS, 2002, p.70). 
De Redelvim, chamado de "anarquista lírico", o amanuense lê sobre os seus amores, suas ideias sociais românticas. Em algumas de suas páginas, Redelvim relata o amor por uma "pequena espanhola". Os amores de Silviano também são por moças de origem espanhola, vide Dolores Gigedo, o "Perrexil", como é espanhol o amor de Dom Quixote, Dulcinéia. Também Sepúlveda gasta seu dinheiro ganho na loteria com uma espanhola, provocando a ira de sua esposa. Espanholas ou não, são as "moças em flor", representantes da juventude efêmera, as inspiradoras de amores desconcertantes. Mais uma vez os termos foram retirados da obra de Proust, cara a Belmiro. No parágrafo 18, intitulado "Um baile das moças em flor", o amanuense relata o constrangimento de não ser notado pelas moças: "As moças não me notavam, mas eu bem as via, para festa dos olhos e malinconia do espírito. Traziam-me uma imagem da vida que foge, e foge sem dó" (ANJOS, 2002, p.63). Belmiro é levado às lembranças de Vila Caraíbas:

Minhas moças em flor de Vila Caraíbas, hoje outoniças, tinham vestidos brancos que modelavam seios morenos e castos. Cantavam ao luar, velhas, inefáveis modinhas. Moças proustianas em flor, que andavam aos bandos e formavam grupos indemarcáveis onde se operava a translação contínua de uma beleza fluida, coletiva e móvel, tal a das virgens da praia de Balbec (ANJOS, 2002, p.63-64).

A vida que foge também é explicada por Silviano, que considera o fáustico de Amiel similar ao de Spengler. Para Silviano, o mito Donzela Arabela é um símbolo fáustico por simbolizar uma aspiração ao imaterial e ao intemporal feminino:

E traduziu para mim o trecho do Also sprache Zarathustra, em que Zarathustra, atravessando a floresta com seus companheiros, encontra raparigas que bailam numa clareira.

- Elas representam a vida, Porfírio, a vida que foge diante do asceta! (ANJOS, 2002, p.71).

Silviano escreve um diário, que intenta publicar, ao final de dez anos. Por não ser possível escrevê-lo todo em latim, apenas os títulos dos capítulos serão nessa língua. 0 pedante professor de literatura lê desde os filósofos até os escritos religiosos, aos quais faz referência constante. Encarna o mito de Dom Juan, por suas aventuras com mulheres. Traça o plano de construir um castelo, onde residirá, comprando o título de Conde de Revila y Gigedo, em homenagem à sua amada Dolores Gigedo, o "Perrexil". Belmiro acredita ser a ideia bem d'annunziana:

Próximo à ponte levadiça, sempre suspensa, ver-se-ia em cartaz: "Domínios privados do Conde de Revila y Gigedo". Uma idéia bem d'annunziana, como se vê. Não é por acaso que conserva um retrato do Poeta sobre a mesa. Retrato autografado, que Ihe trouxeram da Itália (ANJOS, 2002, p.188).

Em conversa com Jandira, Belmiro comenta o episódio ocorrido com Ofélia, na obra Hamlet, de Shakespeare. Jandira mostra-se desapontada com os homens e com a sua situação de moça de carne e osso, sem a proteção de pais e irmãos que a protejam, como as moças em flor, capazes de inspirar lendas românticas. Pensa em "cometer um disparate", 
ao que Belmiro responde que recomendará a D. Hortênsia, mãe dela, para que não deixe o vidro de sublimado ao seu alcance:

- Com sublimado não, Belmiro. Afogar-se é mais romântico. É mais do estilo Belmiriano.

Aproveitei a oportunidade - que ela permitiu, para nos desviarmos de uma conversa melancólica - e continuei no mesmo tom, dizendo-lhe que não só era mais romântico, e também mais conforme à técnica da tragédia. Afogar-se, como Ofélia, num regato, de cuja margem pende um salgueiro (ANJOS, 2002, p.88-89).

Mas, como acontece na passagem em que Belmiro parodia Proust, a conclusão escapa a qualquer tom de tragicidade. Mais uma vez, o amanuense defronta-se com a realidade objetiva, representada pela figura de Jandira, moça avessa às ideias poéticas. Essa linguagem poética, tão própria ao espírito de Belmiro, é alimentada pelas leituras, tal qual ocorre com Dom Quixote. E, como o cavaleiro manchego, o amanuense vê-se confrontado com uma realidade despoetizada:

Jandira não é um temperamento poético e há de fazer restrições à descrição da morte de Ofélia, dizendo não ser fácil aceitarmos que a pobrezinha tenha tido tempo de cantar fragmentos de velhas canções, enquanto se afogava. [...] Mesmo porque, vejo agora ao reler o belo episódio, não houve suicídio. [...] Jandira impugnará, também, a inveja do galho: é um espírito realista, impermeável aos símbolos e à linguagem da poesia. Além disso, acha-se agora sob a esfera de influência do amigo Redelvim, que considera os poetas "traficantes de tóxicos", sustentados pelo capitalismo para entorpecer o espírito de rebeldia das massas... (ANJOS, 2002, p.89).

Outra referência importante ocorre quando da viagem de Belmiro ao Rio de Janeiro, cidade que evoca imagens machadianas amadas na sua adolescência. Como Dom Quixote, o amanuense é inspirado pelos romances, revivendo-os, pelas ruas habitadas pelas personagens de Machado:

Percorrendo a rua de Matacavalos, pensei, com saudade, naqueles cavaleiros que andavam de tílburi, jogavam voltarete e tinham, sobre o mundo, pensamentos sutis. Divisei, a um canto, o vulto amável de Sofia e tive dó do Rubião. A meus ouvidos, mana Rita fazia insinuações (Cale a boca, mana Rita...). Em certo bonde, que me pareceu puxado por burricos, tive a meu lado Dom Casmurro, e lobriguei, numa travessa, dois vultos que deslizavam furtivos à luz escassa dos lampiões: Capitu e Escobar (ANJOS, 2002, p.200).

Mitos infantis, como o da Donzela Arabela, ou da Bela Adormecida, entre outros, estão presentes, além de outras muitas histórias fabulosas. A lenda de Iracema é recordada de forma lírica, bem ao gosto de Belmiro:

Eis o lado melancólico do São João, do Natal e do Ano-Bom. Cada ano, ao vê-los chegar, verificamos que a paisagem do passado vai ficando mais azul, mais distante, como aquela serra que azula no horizonte, além, muito além da qual nasceu Iracema (ANJOS, 2002, p.59). 
O mosaico literário também comporta as composições musicais, já que fazem parte do repertório mítico do protagonista, atuando de forma semelhante às obras literárias, formadoras do seu caráter lírico. Belmiro é constituído por canções e histórias ouvidas na infância e que permanecem no adulto. Lembra-se da "Varsoviana", que na Vila Caraíbas era chamada de "Valsa Viana". Assobia a valsa "Saudades de Ouro Preto", no dia de seu aniversário, após o jantar. Também assobia a "Grande fantasia triunfal sobre o Hino Nacional Brasileiro", composta por Louis Moreau Gottschalk (1829-1869), obra apropriadamente Belmiriana, já que traz a variação de uma composição já existente, como faz o amanuense, o tempo todo, ao longo do diário, em seus pastiches literários. É a partir da canção "Tuorna a Surriento", associada ao aroma da dama-da-noite, que o amanuense relembra o seu amor por Camila. Provê de musicalidade aos seus devaneios romanceados, fazendo-se tocar a "Marcha nupcial" de Mendelssohn, na imaginada cerimônia de casamento de Carmélia com o noivo Jorge. Perde-se em recordações quando ouve um sanfonista, ou uns restos de opereta pelo auto-falante fanhoso:

"Os sons musicais que ainda ouvia não me deixaram perceber o ruído do motor, e só a buzina, seguida de um chiado forte, de freios manobrados com violência, pôde despertar-me", é o que relata o amanuense, acerca de seu encontro com Carmélia casada. (ANJOS, 2002, p.227).

No baile de Carnaval, arrastado pelos foliões, Belmiro põe-se, ridiculamente, a entoar uma velha canção de Vila Caraíbas. O grupo, porém, cantava outra composição: "Lembra-me que homens e mulheres, a um de fundo, mãos postas nos quadris do que ia à frente, dançavam, encadeados, e entoavam os coros sensuais que descem do Morro. Eram cantigas bem tristes, que vinham da carne" (ANJOS, 2002, p.37-38). No sonho, relatado ao final do diário, o poeta sem nome cantarola a canção infantil "Pirolito que bate, bate...".

Ao ouvir um sanfonista, Belmiro põe-se a refletir acerca da própria função da arte, atribuindo ao artista o poder de transmitir às outras pessoas, como se fossem delas, as suas mágoas individuais, "proporcionando ao espírito válvulas por onde se evadem as emoções que o comprimem, a expressão - seja musical, literária ou plástica - alivia-o docemente" (ANJOS, 2002, p.33-34):

O artista se revelava por esta forma perfeito, extraindo, dos seus motivos individuais, necessidades ajustadas às necessidades da alma dos circunstantes, que ali iam buscar expressão para sentimentos indefiníveis que os povoavam e só se traduziriam por frases musicais (ANJOS, 2002, p.33).

Para concluir, é necessário lembrar que a leitura, como a narração de histórias e as canções, comportam uma função mitológica, como explica Mircea Eliade. A leitura substitui a narração dos mitos nas sociedades arcaicas, sendo que, graças à leitura, o homem moderno consegue obter uma "saída do tempo" comparável à propiciada pelos mitos (ELIADE, 2001, p.167). A leitura de "trechos" à mesa das refeições, pelo pai do narrador das memórias de $A$ menina do sobrado ocupa o lugar das recitações orais, vivas nas comunidades rurais da Europa.

Como observa Eliade, nas sociedades modernas, a prosa narrativa, especialmente o romance, ocupou o lugar antes pertencente à recitação dos mitos e dos contos nas 
sociedades tradicionais. Eliade explica que é possível dissecar a estrutura "mítica" de certos romances modernos, demonstrando, assim, a sobrevivência literária dos grandes temas e das personagens mitológicas. Dessa forma, pode-se dizer que a paixão moderna pelos romances trai o desejo de ouvir o maior número possível de "histórias mitológicas" dessacralizadas ou simplesmente camufladas sob formas "profanas" (ELIADE, 2006, p.163164). Assim como outros gêneros literários, a narrativa épica e o romance prolongam, em outro plano e com outros fins, a narrativa mitológica. Em ambos os casos, trata-se de contar uma história significativa, de relatar uma série de eventos dramáticos ocorridos num passado mais ou menos fabuloso.

Por meio da literatura, Belmiro cria um mundo próprio, verdadeiro, além de, com as canções populares, realizar uma "saída do tempo", desprendendo-se de seu cotidiano, deslocando-se para lugares longínquos, no tempo e no espaço, a sua infância em Vila Caraíbas, com suas festas e canções. A "saída do tempo" produzida pela leitura particularmente pela leitura de romances - é o que mais aproxima a literatura das mitologias. Segundo Eliade, é na literatura que se pode verificar, de modo mais intenso que nas outras artes, a revolta contra o tempo histórico e o desejo de atingir outros ritmos temporais além daquele em que as pessoas são obrigadas a viver e a trabalhar:

Os traços de tal comportamento mitológico revelam-se igualmente no desejo de reencontrar a intensidade com que se viveu, ou conheceu, uma coisa pela primeira vez; de recuperar o passado longínquo, a época beatífica do "princípio". É sempre a mesma luta contra o Tempo, a mesma esperança de se libertar do peso do "Tempo morto", do Tempo que destrói e que mata (ELIADE, 2006, p.170).

Justamente contra o tempo que destrói e que mata, é que se insurge Belmiro, que chega aos trinta e oito anos preocupado com seu futuro sem um amor, como o de Carmélia mitificada. A juventude adorada é recordada com nostalgia pelo homem a quem a idade vai dominando. À juventude e às moças em flor canta o amanuense, em seu velho escritório, os versos de Molière, proporcionando ao mosaico literário um momento de sublime beleza e lirismo:

"Profitez du printemps

de vos beaux ans,

aimable jeunesse;

Profitez du printemps..."

“... La beauté passe,

le temps l'éfface,

l'âge de glace

vient à sa place,

Qui nous ôte le goût de ces doux passe-temps."

(ANJOS, 2002, p.219) 


\section{REFERÊNCIAS BIBLIOGRÁFICAS}

ANJOS, C. dos. O amanuense Belmiro. Rio de Janeiro: Garnier, 2002.

A menina do sobrado. Rio de Janeiro: Garnier, 1994.

BERARDINELLI, A. "L'incontro con la realtà". In: MORETTI, F. II romanzo. Le forme. V. II. Turim: Einaudi, 2002.

ELIADE, M. Mito e realidade. São Paulo: Perspectiva, 2006.

. O sagrado e o profano. São Paulo: Martins Fontes, 2001.

LUKÁCS, G. A teoria do romance. São Paulo: Duas Cidades; Editora 34, 2000.

MAGRIS, C. "È pensabile il romanzo senza il mondo moderno?". In: MORETTI, F. Il romanzo. La cultura del romanzo. V. I. Turim: Einaudi, 2001.

ORTEGA Y GASSET, J. Meditações do Quixote. São Paulo: Livro Ibero-Americano, 1967.

SAAVEDRA, M. de C. Don Quijote de La Mancha. 2 Vol. Barcelona: Biblioteca de la Literatura Universal, 2000.

WATT, I. Mitos do individualismo moderno. Rio de Janeiro: Jorge Zahar, 1997.

Artigo recebido em: 27/06/09

Artigo aprovado em: 03/09/09

Referência eletrônica: TAMURA, Celia. "O Mosaico Literário em O Amanuense Belmiro", Revista Criação \& Crítica (online), n. 3, p.57-65, 2009. 